\title{
Fuzzy Logic Controller for an EV's Dual-Source Hybridization
}

\author{
Hatim Jbari*, Mohamed Haidoury ${ }^{\dagger}$, Rachid Askour ${ }^{\star}$ and Badr Bououlid Idrissi $^{\S}$ \\ Modeling, Information Processing and Control Systems (MPICS), National High School of Arts and Crafts of Meknes (ENSAM- \\ Meknès), Moulay Ismaïl University, Morocco
}

\begin{abstract}
This paper presents an energy management system (EMS) based on fuzzy logic control (FLC) strategy combined with power filtering. This strategy is developed for an Electric Vehicle (EV) hybrid energy storage systems (HESS). The proposed control and energy management strategy (EMS) aims to ensure an efficient power split guaranteeing that battery and supercapacitors (SC) provide the continuous and transient- power, respectively, adopting a pure electric vehicle fully-active parallel topology. In order to develop the studied system model, the Energetic Macroscopic Representation (EMR) approach is adopted. Considering SC's control criterion, and battery root mean square RMS current reducing, an evaluation of the proposed EMS and developed model was conducted using MATLAB/SIMULINK simulation under New European Driving Cycle (NEDC) and compared to the classical only battery storage configuration.
\end{abstract}

\section{Introduction}

The industrial revolution of the 19th and 20th centuries was marked by a radical change in transportation. The $20^{\text {th }}$ century, in particularly, was dominated by significant development of the automotive industry, a means of transport that is almost entirely based on the use of fuel. As a consequence, transport generates the second largest share of greenhouse gas emissions in the world, after energy and electricity production during 2016. Three-quarters of transport emissions are caused by trucks, buses and cars according to the IEA [1].

The EV is generally considered the most effective solution for environment-related problems. Nevertheless, this environmentally-friendly vehicle faces several important problems, including autonomy, size, battery cost and limited battery lifetime [2]. However, in the recent years, scientists have developed some solutions to face these challenges, such as the use of SCs and the design of an efficient EMS in order to restrain the factors affecting the battery performances [3-5].

The energy management strategy, also called EMS, defines the power flow distribution among the various components of the HESS. This process is generally based on predefined optimisation criteria, to assure an efficient power split between battery and SCs, and make the most of the complementarity among the HESS's sources. Battery degradation minimization, extending battery lifetime and improving vehicle range are the main criteria to satisfy.

The literature review [5-6] shows three approaches to develop an efficient EMS [6-8]: the Rule-based (RB) control strategy includes fuzzy-logic and deterministic EMS. It's based on expertise or knowledge of the system components characteristics, using predefined rules. The $\mathrm{RB}$ control strategy doesn't require previous knowledge of the trip, which explain the advantage of simple control implementation. EMS based on deterministic optimisation methods, aims the minimisation (or maximisation) of a performance criteria. Finally, EMS based on stochastic optimisation methods, such as machine learning, which provides the capacity to learn, in order to reach an objective.

Researchers in [9] used a fuzzy logic approach to control an EV's HESS based on a semi-active topology. The objective of the developed EMS is the battery lifetime optimisation, using a semi-empirical model, taking into consideration the ambient temperature influence. A recent work in [10], aims to integrate SCs in a fully battery-powered, three wheeled vehicles. The proposed hybridisation is based on an active parallel topology. The FLC control is implemented in this configuration in order to design an upgraded version of the existing vehicle and reduce the battery load. The work of [11] proposes an EMS, based on a FLC controller, taking into consideration the battery degradation. This strategy aims to improve the battery lifetime, based on its degradation model, and related to battery's State of Charge (SoC) variations induced by charge/discharge cycles.

This work aims the energy optimisation of a HESS, combining a lithium ion battery and SCs, for an EV. The complementarity between the HESS energy sources enhances the system performances. This study focuses on the implementation of advanced control and energy

\footnotetext{
* Corresponding author: hatim.jbari@gmail.com

$\dagger$ Corresponding author: haidoury.mohamed@gmail.com

¥ Corresponding author: r.askour@umi.ac.ma

$\S$ Corresponding author: b.bououlid@umi.ac.ma
} 
management techniques, such as FLC combined with power filtering.

The paper is structured as follows. Section II describes the proposed EV model and control. Section III presents the developed FLC strategy. Section IV presents the simulation results and discussion of evaluation and performances of the proposed strategy.

\begin{tabular}{|c|c|}
\hline$A_{a e}$ & Vehicle Frontal Area $\left(\mathrm{m}^{2}\right)$ \\
\hline C & DC Capacitor Capacitance (F) \\
\hline$C_{\text {bat }}$ & Battery pack equivalent Capacitance $(\mathrm{F})$ \\
\hline$C_{x}$ & Drag coefficient \\
\hline $\mathbf{F}_{\mathrm{ae}}$ & aerodynamic force $(\mathrm{N})$ \\
\hline$F_{\text {eq }}$ & equivalent force $(\mathrm{N})$ \\
\hline$f_{\mathrm{fr}}$ & coefficient of friction \\
\hline $\mathrm{Frl}_{\mathrm{rl}}$ & rolling force $(\mathrm{N})$ \\
\hline $\mathrm{i}_{\text {bat }}$ & battery current $(A)$ \\
\hline $\mathbf{I}_{\text {bat_meas }}$ & battery measured current $(A)$ \\
\hline $\mathbf{I}_{\text {bat_ref }}$ & battery current reference $(A)$ \\
\hline $\mathbf{i}_{\text {ch_bat }}$ & $D C-D C$ battery Current converter $(A)$ \\
\hline $\mathbf{i}_{\text {ch_bat_meas }}$ & $D C-D C$ batt.convert. measured Current $(A)$ \\
\hline $\mathbf{i}_{\text {ch_sc }}$ & DC-DC SC Current converter (A) \\
\hline $\mathbf{i}_{\text {ch_sc_ref }}$ & DC-DC SC converter Current reference $(A)$ \\
\hline $\mathrm{i}_{\mathrm{DC}}$ & DC BUS Current $(A)$ \\
\hline $\mathbf{I}_{\mathrm{DC} \_ \text {meas }}$ & DC BUS measured Current (A) \\
\hline $\mathbf{i}_{\text {hess }}$ & HESS Current (A) \\
\hline $\mathbf{I}_{\text {hess_ref }}$ & HESS Current reference $(A)$ \\
\hline $\mathbf{i}_{\mathrm{sc}}$ & SC current $(A)$ \\
\hline $\mathbf{i}_{\text {sc_meas }}$ & SC measured current $(A)$ \\
\hline $\mathbf{i}_{\text {sc_ref }}$ & SC current reference $(A)$ \\
\hline $\mathbf{L}_{\text {bat }}$ & Battery inductor inductance $(\mathrm{H})$ \\
\hline $\mathrm{L}_{\mathrm{sc}}$ & SC inductor inductance $(\mathrm{H})$ \\
\hline $\mathbf{P}_{\text {tract_ref }}$ & Traction drive power (W) \\
\hline $\mathbf{Q}_{\text {bat }}$ & Battery electric charge (C) \\
\hline$r_{\text {bat }}$ & battery series resistance $(\Omega)$ \\
\hline$r_{L_{-} \text {bat }}$ & inductor series resistance $(\Omega)$ \\
\hline $\mathrm{r}_{\mathrm{L}-\mathrm{sc}}$ & inductor series resistance $(\Omega)$ \\
\hline SOC $_{\text {bat }}$ & Battery State Of Charge (\%) \\
\hline $\mathrm{SOC}_{\mathrm{sc}}$ & SC State Of Charge (\%) \\
\hline $\mathrm{U}_{\text {bat }}$ & battery voltage $(\mathrm{V})$ \\
\hline $\mathrm{U}_{\mathrm{DC}}$ & DC BUS voltage $(\mathrm{V})$ \\
\hline $\mathrm{U}_{\mathrm{DC} \_ \text {meas }}$ & DC BUS measured voltage $(\mathrm{V})$ \\
\hline$U_{D C}$ ref & DC BUS voltage reference (V) \\
\hline $\mathrm{U}_{\mathrm{L} \_ \text {bat }}$ & Battery inductor voltage $(\mathrm{V})$ \\
\hline$U_{L \_ \text {bat_ref }}$ & Battery inductor voltage reference $(\mathrm{V})$ \\
\hline$U_{L_{-} s c}$ & SC inductor voltage $(\mathrm{V})$ \\
\hline$U_{L_{-} \text {sc_ref }}$ & SC inductor voltage reference $(\mathrm{V})$ \\
\hline $\mathrm{U}_{\mathrm{sc}}$ & SC voltage (V) \\
\hline $\mathrm{U}_{\text {sc_meas }}$ & Measured SC voltage (V) \\
\hline $\mathrm{V}_{\text {ref }}$ & EV speed reference $(\mathrm{m} / \mathrm{s})$ \\
\hline $\mathbf{v}_{\mathrm{w}}$ & Wing speed (m/s) \\
\hline$\alpha$ & Slope (\%) \\
\hline $\boldsymbol{\alpha}_{\text {bat }}$ & DC-DC battery converter duty cycle \\
\hline$\alpha_{\mathrm{sc}}$ & DC-DC SC converter duty cycle \\
\hline $\boldsymbol{\alpha}_{\text {sc_meas }}$ & DC-DC SC converter measured duty cycle \\
\hline$\eta_{\text {ch_bat }}$ & DC-DC Battery converter efficiency \\
\hline$\eta_{\text {ch_sc }}$ & DC-DC SC converter efficiency \\
\hline
\end{tabular}

\section{Modelling and control of the HESS}

The studied EV, is a full-electric $4 \times 2$ SUT (sport utility truck), of $2800 \mathrm{~kg}$ (Figure 1), used for the goods distribution in urban areas. This vehicle is powered by a HESS equipped with a Li-ion battery (Table 1) and SCs (Table 2) [12], that provides an urban autonomy of 150 $\mathrm{km}$ and a maximum speed of $100 \mathrm{~km} / \mathrm{h}$.

Table 1. Characteristics of the battery sources

\begin{tabular}{|c|c|c|c|}
\hline $\begin{array}{c}\text { Battery } \\
\text { Li-Ion (3.7V) }\end{array}$ & Symbol & Value & Unit \\
\hline SoC Limits & SoC batt & {$[30,100]$} & $\%$ \\
\hline $\begin{array}{c}\text { Energy } \\
\text { density }\end{array}$ & $\rho_{\text {batt }}$ & 160 & $\mathrm{Wh} / \mathrm{kg}$ \\
\hline total mass & $\mathrm{M}_{\text {bat }}$ & 153 & $\mathrm{Kg}$ \\
\hline energy & Ebatt & 654 & $\mathrm{Ah}$ \\
\hline
\end{tabular}

Table 2. Characteristics of the SC's sources (GTCAP GTSPP-2R7-508UT)

\begin{tabular}{|c|c|c|c|}
\hline SC (2.7V) & Symbol & Value & Unit \\
\hline Capacitance & $\mathrm{C}_{\mathrm{sc}}$ & 5000 & $\mathrm{~F}$ \\
\hline ESR & $\mathrm{R}_{\mathrm{sc}}$ & 0.21 & $\mathrm{~m} \Omega$ \\
\hline SoC Limits & $\mathrm{SoC}_{\mathrm{sc}}$ & {$[50,100]$} & $\%$ \\
\hline
\end{tabular}

This study focuses on the modelling, control and command of EV's HESS. Thus, the powertrain is considered as an equivalent sub-system (Figure 1), using a controlled current reference input.

\subsection{HESS modelling}

Batteries, SCs and energy converters Models, are an essential tool for the HESS-powered systems design (Figure 1). They are used for the energy sources characterisation, such as the state of charge (SoC) estimation of both sources, and the state of health $(\mathrm{SoH})$, especially for battery, considering its role as the main source and its considerable cost.

Battery model: The battery pack is used as a primary source, with high energy density. The dynamic battery model is simplified and considered as a large capacitor with a very high capacity $30000 \mathrm{~F}$ and an internal resistance $r_{\text {bat. }}$ Q $Q_{b a t}$ is the nominal capacity, $t_{0}$ represents the initial time, and the battery $\mathrm{SoC}$ is calculated using ampere-hour integration [13].

SC model: The SC-pack represents the secondary power source. The considered SC's model in the studied system, is based on a series circuit $\mathrm{R}_{\mathrm{ESR}}-\mathrm{C}$, where $\mathrm{R}_{\mathrm{ESR}}$ represents the equivalent series resistance [14], and $C$ the equivalent SC's capacitance. 


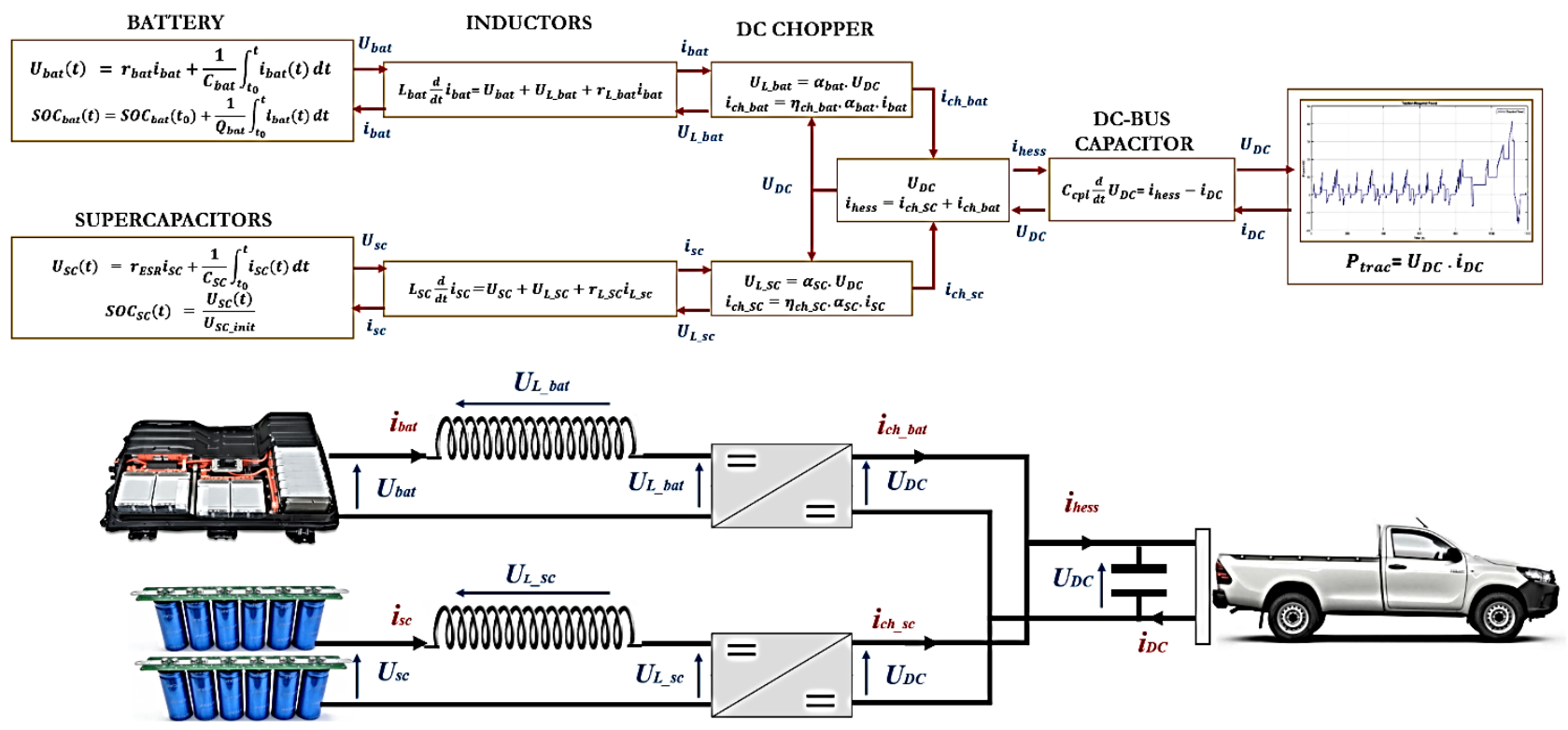

Fig. 1. EV system and mathematical models of the components of HESS

The $\mathrm{SoC}_{\mathrm{sc}}$ is calculated using the ratio of SCs voltage $\mathrm{U}_{\mathrm{sc}}$, applied across $\mathrm{SC}$, and the initial voltage $\mathrm{U}_{\text {sc } \_ \text {init. }}$ Moreover, the nominal half-voltage is defined as the low limit voltage [15-16].

Smoothing inductor model: The inductor is a passive component that stores electrical energy in the form of an electromagnetic energy, when electric current flows through it. It is modelled as a series R-L circuit. To simplify the model, smoothing magnetic saturation isn't considered, the inductance current is considered as a state variable.

DC-DC converter model: In the proposed configuration, battery and SCs are equipped with two converters to interface with the DC bus. The used DCDC converters are bidirectional choppers. The converters models are shown in Figure 2. In this case, the average model is considered [17], which takes into consideration the efficiencies of the DC-DC converters: $\eta_{\text {ch_bat, }} \eta_{\text {ch_sc }}$, with modulation ratios $\alpha_{\text {bat }}, \alpha_{\text {sc. }}$.

DC capacitor model: The DC bus capacitor is a key element for the voltage source inverter (VSI) that controls the traction machine. It provides power decoupling between the DC and AC sources. The capacitor stores and releases energy. It provides an instantaneous power alternation capability between the DC-DC converter and the inverter, allowing the system to support the HESS's power variation. The $U_{D C}$ voltage is considered as a state variable to control in the studied system.

Traction subsystem model: The traction subsystem is represented by an equivalent power $\mathrm{P}_{\text {trac }}$, controlled by DC current. $P_{\text {trac }}$ takes into consideration the efficiency of the energy conversion chain, i.e. mechanical transmission, electric machine and VSI. The power profile is deduced from NEDC speed and resultant force (1) of vehicle applied forces (2) (3) (4) (5).

$$
\begin{aligned}
& F_{e q}=P_{e v}+F_{r l}+F_{a e}+F_{\text {inert }} \\
& P_{e v}=m g \sin (\alpha) \\
& F_{r l}=f_{f r} m g \\
& F_{a e}=\frac{1}{2} \rho A_{a e} C_{X}\left(\mathrm{v}_{\mathrm{ev}}^{2}+\mathrm{v}_{w}^{2}\right)
\end{aligned}
$$

\subsection{HESS control}

The EMR is a graphical tool providing a complex system representation (electrical, mechanical, thermal, chemical, fluidic, etc.). It is an efficient approach to describe complex electromechanical systems. The EMR uses graphical blocks to describe subsystems behaviours such as the source, storage, multi/mono-physical converter and coupling element (orange blocks). EMR is based on the action and reaction principle, used to organise the interactions of different subsystems, according to their physical causality (integral causality) [18]. Furthermore, the system Maximum Command Structure (MCS), highlights the control layer, it can be systematically deduced using inversion rules of system model's EMR.

Thus, control level is simply deduced by inverting the EMR level of system model [19, 20] (Figure 2). The control level ensures that the controlled variables $\left(\mathrm{U}_{\mathrm{DC}}\right.$, $\left.i_{\text {hess, }}, i_{\text {bat }}, i_{\text {sc }}\right)$ follow their reference values defined by EMS. The Maximum Control Structure (MCS) is constructed considering all measurable parameters. 


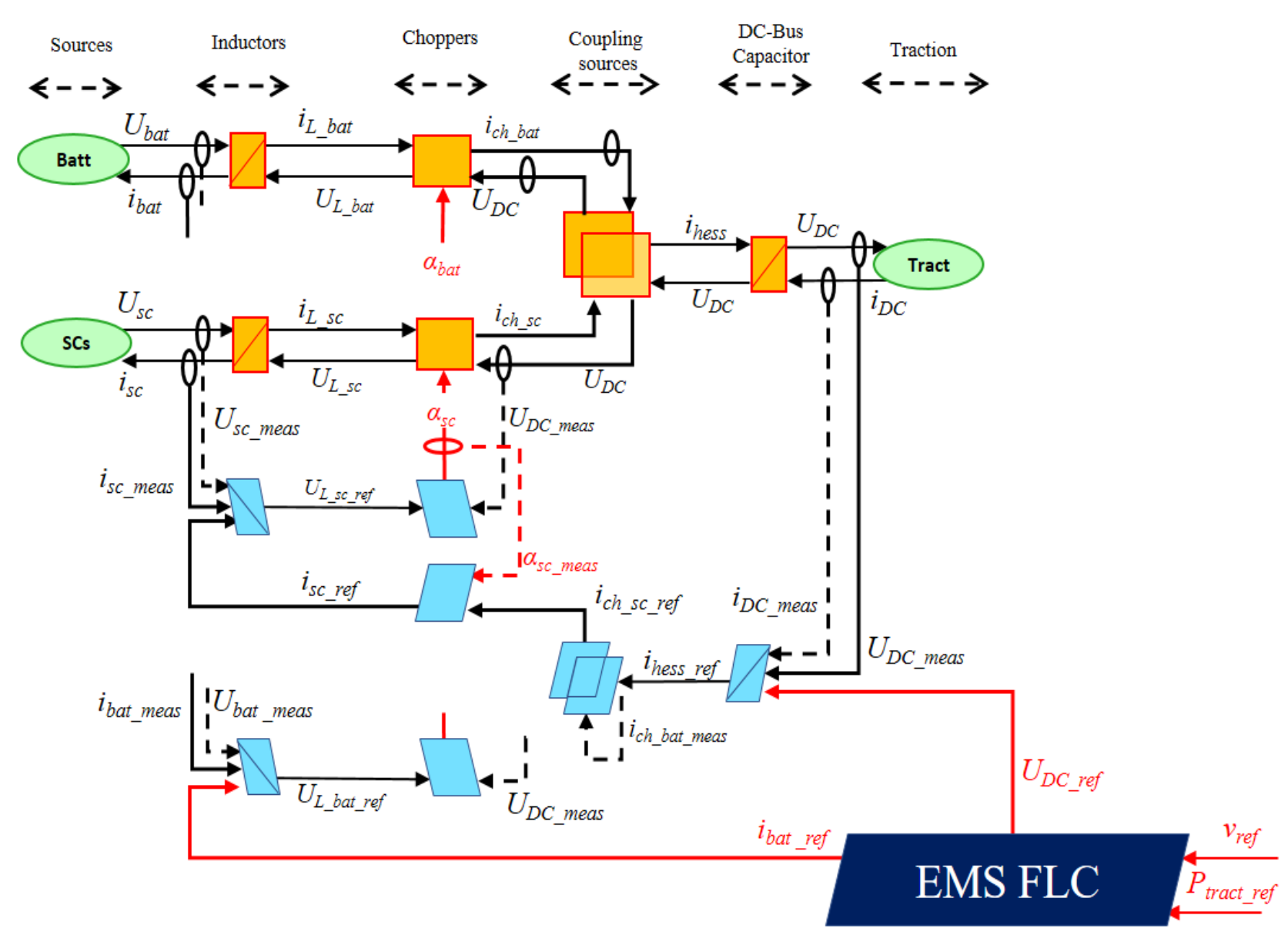

Fig. 2. EMR and MCS of the studied system

The various elements of the control layer are represented by parallelograms in light blue, which are constructed according to the inversion rules [21]:

- The choppers (conversion elements) are directly inverted, deduced by a direct mathematical models inversion;

- The DC-bus capacitor and inductors (storage elements) are inverted indirectly using PID controllers, output measurements and a possible disturbance measurement;

- The SC and battery currents node (coupling element) is inverted using a distribution or weighting criterion.

\section{Proposed Fuzzy Logic Control Strategy}

The main objective of the developed EMS, illustrated in Figure 3, is to ensure continuously the requested power along a mission profile, reducing the battery degradation as much as possible. Thus, to achieve these objectives, EMS should efficiently define the energy flows between both sources (batteries, SC). This can be accomplished by defining an appropriate battery current reference (ibatt ref), which limits its stress by controlling the progressive contribution of each source, and the DC bus voltage reference, which should be kept stable to satisfy the drive train power requirement. The implementation of these operations must take into account the real-time sources performances, in particular the SC's SoC, which should be maintained in an optimal range to keep their energy performance.

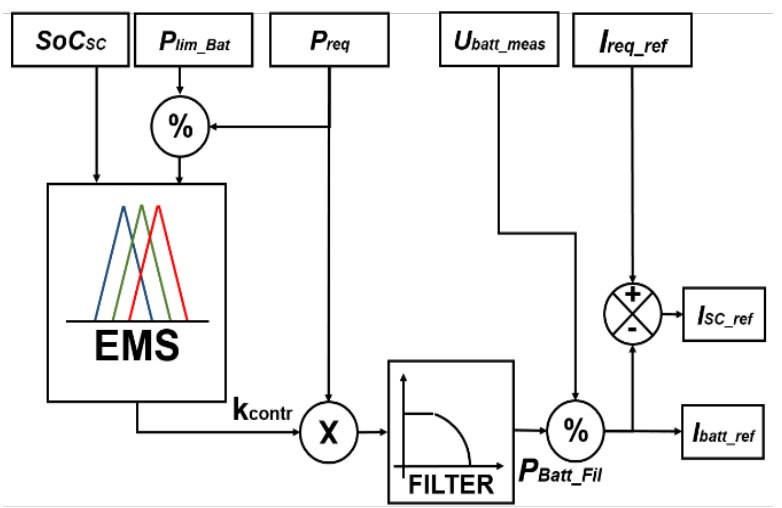

Fig. 3. EMS Strategy

The studied EV is considered more suitable for the goods distribution in urban areas. This road trip requires many stops and starts cycles. Thus, this driving cycle offers a large quantity of recoverable energy during braking, and a high power requirement during acceleration. Moreover, power limitation and battery's charge/discharge $\left(\mathrm{SoC}_{\mathrm{bat}}\right)$ cycle's reduction are taken 
into consideration in the developed EMS. These factors reduce the battery performances. In addition, the use of SCs in combination with battery packs, enables absorption of power peaks. This makes SCs a great asset in electric propulsion, to satisfy relatively high transient power demands, e.g. for braking energy recovery and fast acceleration.

Indeed, the developed EMS should ensure:

- The recovered energy generated by braking system (when: $\mathrm{P}_{\text {dem }} / \mathrm{P}_{\text {lim }}<0$ ), should be taken by $\mathrm{SCs}$, particularly the power peaks.

- The handling of constant power requirement should be taken by battery;

- High power response during acceleration phase should be taken by the SCs (when: $\mathrm{SoC}_{\mathrm{sc}} \in[50 \%, 100 \%]$ and $\mathrm{P}_{\mathrm{dem}}<\mathrm{P}_{\text {lim }}$ ).

Thus, the proposed EMS uses a FLC-controller, the structure of the strategy is illustrated in Figure 4. This controller supports two inputs $\left(\mathrm{SOC}_{\mathrm{sc}}, \mathrm{P}_{\mathrm{dem}} / \mathrm{P}_{\mathrm{lim}}\right)$, and one output $\mathrm{k}_{\text {cont }}$ which defines the contribution of each energy source.

Fuzzification

This operation is based on a numerical data transformation to a linguistic variable. Hence, membership functions have been defined for the fuzzy system, four functions for the power ratio (LOW, NORMAL, HIGH, VERY-HIGH), five for the $\mathrm{SOC}_{\mathrm{uc}}$ (UNDER-ZERO2, UNDER-ZERO1, ZERO, NORMAL, HIGH), and five for the output represented by $k_{\text {cont }}$ (BEYOND-SYSTEM, ALONE, HALF, KEEP, $\mathrm{HIGH})$.

The membership function is used to define the degree of membership of numerical data to various linguistic variables.

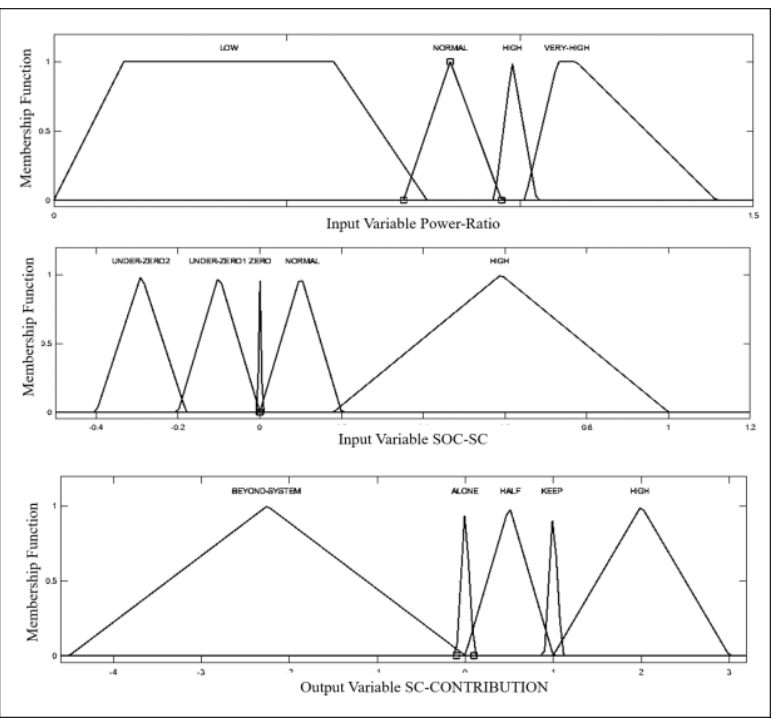

Fig. 4. Developed membership functions

\section{- Inference}

The fuzzy rules are based on the Mamdani-inference mechanism. Thus, with exact and detailed knowledge of the EV's behavior and sources that make up the HESS, the different heuristic rules are expressed in fuzzy domains (Table 3). After the input fuzzification phase, a fuzzy inference machine is defined by the IF-THEN rules, relating the inputs to the output.

Table 3. Rule-base of Fuzzy Logic Controller

\begin{tabular}{|c|c|c|c|c|}
\hline SOC $_{\text {sc }}$ & LOW & NORMAL & HIGH & $\begin{array}{c}\text { VERY } \\
\text { HIGH }\end{array}$ \\
\hline $\begin{array}{c}\text { UNDER- } \\
\text { ZERO2 }\end{array}$ & $\begin{array}{c}\text { BEYOND } \\
\text { SYSTEM }\end{array}$ & $\begin{array}{c}\text { BEYOND } \\
\text { SYSTEM }\end{array}$ & $\begin{array}{c}\text { BEYOND } \\
\text { SYSTEM }\end{array}$ & $\begin{array}{c}\text { BEYOND } \\
\text { SYSTEM }\end{array}$ \\
\hline $\begin{array}{c}\text { UNDER- } \\
\text { ZERO1 }\end{array}$ & $\begin{array}{c}\text { BEYOND } \\
\text { SYSTEM }\end{array}$ & ALONE & ALONE & ALONE \\
\hline ZERO & HIGH & HIGH & HALF & ALONE \\
\hline NORMAL & HIGH & KEEP & ALONE & ALONE \\
\hline HIGH & KEEP & HALF & ALONE & ALONE \\
\hline
\end{tabular}

- Defuzzification

This phase consists of linguistic variables conversion, of the output to numerical values, which define the contribution of each energy sources shown in Figure 5. This operation ensures a stable DC-bus voltage, which supplies the powertrain.

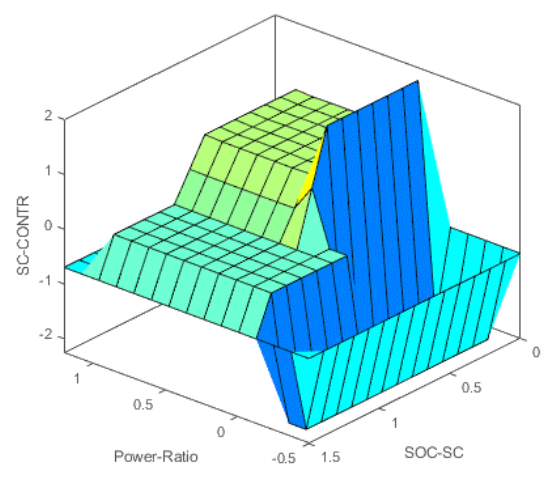

Fig. 5. Output SCs contribution.

The developed EMS uses a filter for the battery current reference (Figure 3). The purpose of using a filter is to divide the power requirement into a low frequency component for battery current reference, and a high frequency component for SCs current reference.

\section{SIMULATION RESULTS}

The simulation model has been constructed in MATLAB/SIMULINK environment and tested under NEDC driving cycle. The initial $\mathrm{SoC}_{\mathrm{sc}}$ and $\mathrm{SoC}_{\mathrm{bat}}$ is $95 \%$.

The first criterion to the developed EMS performances evaluation, is the control of the $\mathrm{SoC}_{\mathrm{sc}}$ respecting the interval that guarantees its energy efficiency, and its role as a perfect energy buffer. Thus, as is shown in Figure 6, the value of $\mathrm{SoC}_{\mathrm{sc}}$ in the initial state $\mathrm{SoC}_{\mathrm{sc}}\left(\mathrm{t}_{0}\right)$ is equal to $\mathrm{SoC}_{\mathrm{sc}}$ in the final state $\mathrm{SoC}_{\mathrm{sc}}\left(\mathrm{t}_{\mathrm{f}}\right)=95 \%$. The variation's range of this parameter respects the limits defined in the strategy: $\mathrm{SoC}_{\mathrm{sc}} \in[75 \%$, $100 \%$ ] still greater than $50 \%$. 

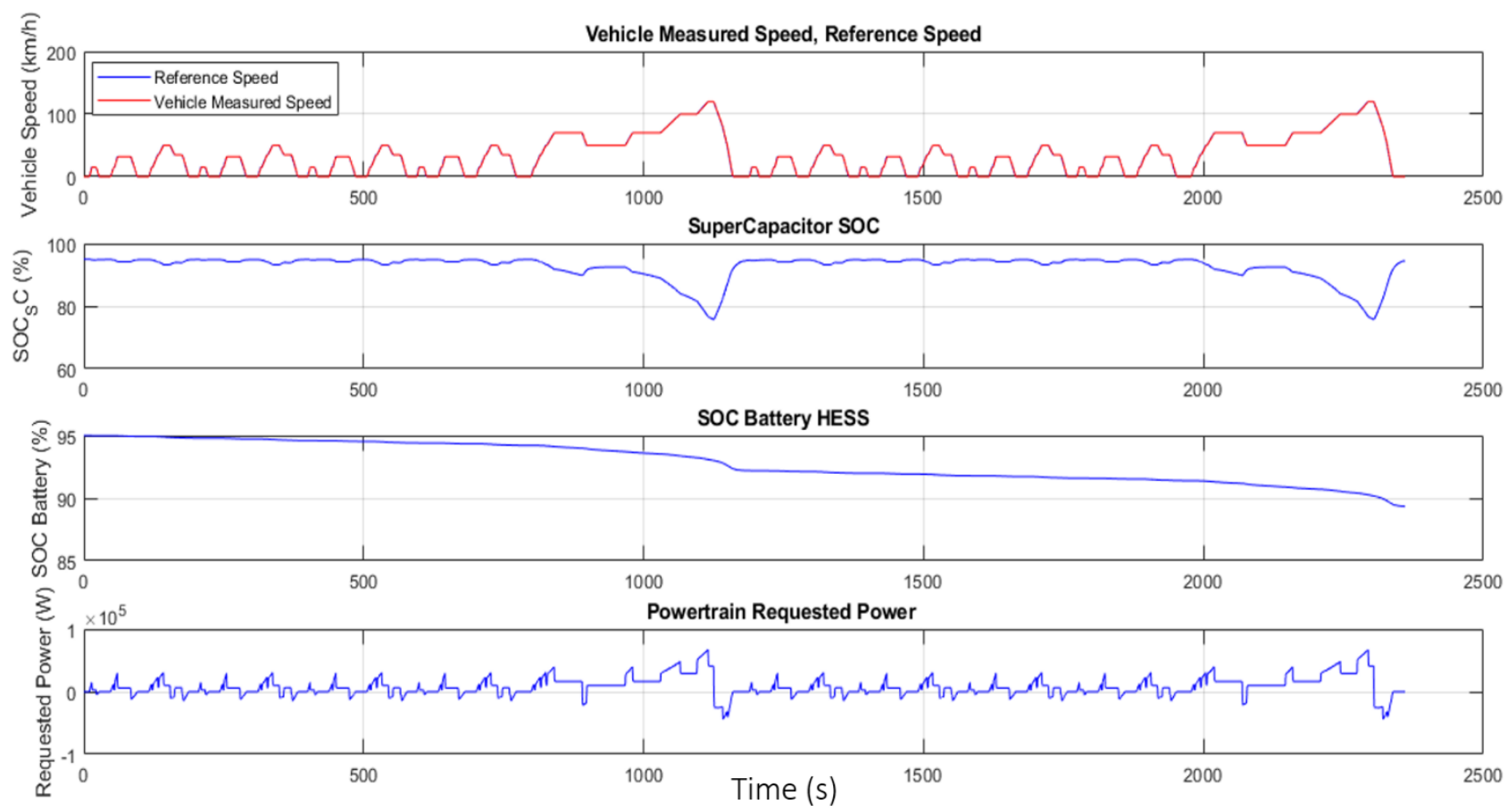

Fig. 6. Simulation results of the EV Hybrid ESS for NEDC

The EMS second evaluation criterion, consists in the respect of the requirements fixed in the inference rules. The global behaviour of the system shows that the $\mathrm{SoC}_{\mathrm{sc}}$ is restored to its initial $\mathrm{SoC}$, without compromising the execution of the considered cycle, and keeping the DCbus voltage constant $\mathrm{V}_{\mathrm{DC}}=160 \mathrm{~V}$, without exceeding the imposed battery power limit $\left(\mathrm{P}_{\text {lim }}=72 \mathrm{~kW}\right)$.

Indeed, according to Figure 7, all the rules were respected during the simulation using the NEDC cycle: - During braking: SCs recover the energy generated during braking: $\mathrm{t} \in[22,27] \mathrm{s}, \mathrm{t} \in[84,95] \mathrm{s}, \mathrm{t} \in[154$, $162] \mathrm{s}$ and $\mathrm{t} \in[175,200] \mathrm{s}$, which is relatively significant due to the kinetic energy of the vehicle, enabling the energy efficiency of the HESS to be improved.

- During constant and quasi-constant speed: the battery supports the constant power demand that has very low impact on its performances: $t \in[14,22] \mathrm{s}, \mathrm{t} \in[60,84] \mathrm{s}$, $\mathrm{t} \in[142,154] \mathrm{s}$ and $\mathrm{t} \in[162,175] \mathrm{s}$.

- During acceleration: the application of hybridization design on this type of vehicle, via the integration of a source characterized by fast dynamics, made it possible to satisfy the high power requirements in a short period of time, an operation that the EMS ensured via the use of the SCs: $t \in[10,14] \mathrm{s}, \mathrm{t} \in[50,60] \mathrm{s}$ and $\mathrm{t} \in[117$, 142]s.

- Reduction of severe battery charging/discharging cycles: according to Figure 6, the frequency of battery cycling is reduced by the SCs integration that supports the transient phases of the driving cycle.

Figure 8 shows the battery supplied currents calculated for the three control strategies, i.e. combined FLC-filtering based control, filtering based control, and conventional battery only control.

Thus, the Combined FLC-Filtering based control is the most efficient strategy for NEDC cycle. The RMS value of the battery current is reduced by $7 \%$, more than the value obtained using filtering alone, which is around $5.3 \%$.

As shown in Figure 8, the battery current is relatively smooth. The proposed strategy limits the current peaks, which are harmful for the battery lifetime, during low speeds $(\mathrm{Vve}<100 \mathrm{~km} / \mathrm{h})$. However, current peaks appear during high speeds (Vev $>100 \mathrm{~km} / \mathrm{h})$, which justifies the limited performance in the vehicle specifications $\left(\mathrm{V}_{\text {ev_max }}=100 \mathrm{~km} / \mathrm{h}\right)$.

\section{Conclusion}

The objective of this work is to have a better use of the HESS supplying a P-EV. In this context, the adopted approach aims to optimise the real-time energy management of electrical sources: battery and SC. This EMS takes into account the electrical factors that influence the battery performance.

A comparative study of the advantages of the proposed configuration and control, was conducted using simulation under the NEDC driving cycle, this study has evaluated the performance of the proposed system by comparing its performances with the conventional configuration based on a battery alone. The simulation results show that the proposed solution effectively provides SC control and limits battery degradation, reducing battery RMS value and current peaks.

Future work will focus on the development of an FLC-EMS based on a battery degradation model, using the chemical and thermal dynamics of the battery. 

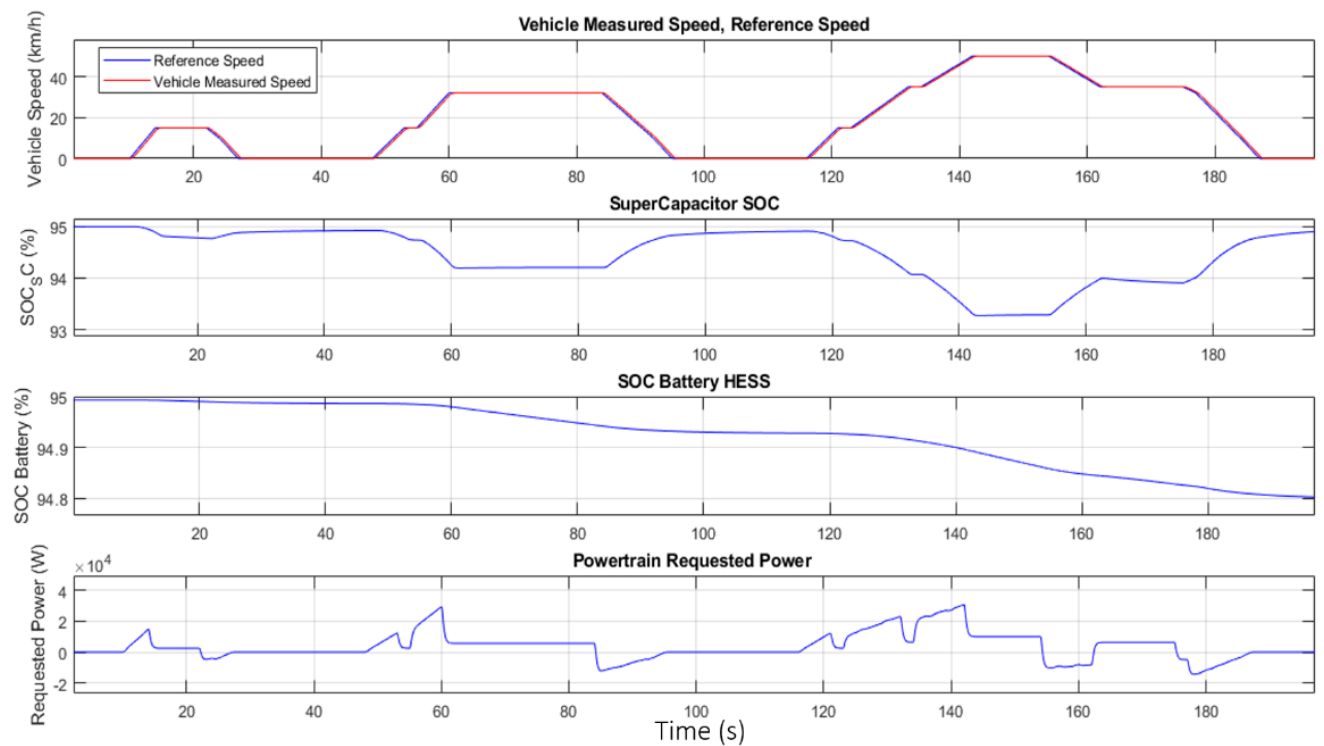

Fig. 7. Simulation results of the EV Hybrid ESS for ECE Cycle (NEDC $t \in[0,200] \mathrm{s}$ ).

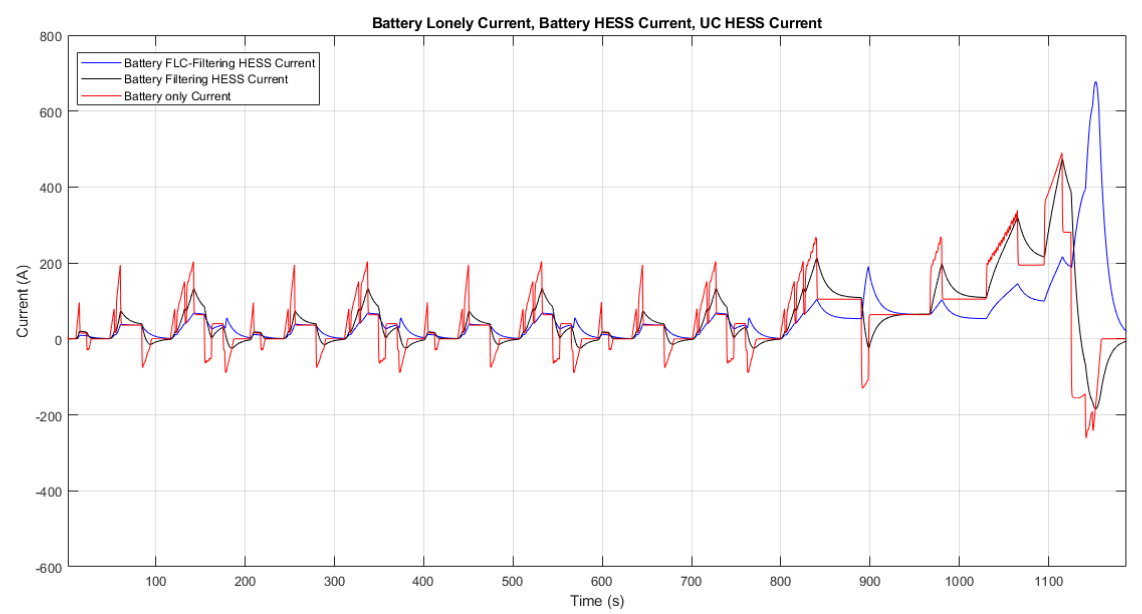

Fig. 8. Battery current comparison between the EMSs and the battery only architecture

\section{APPENDIX: Pictograms of Energetic Macroscopic Representation (EMR)}

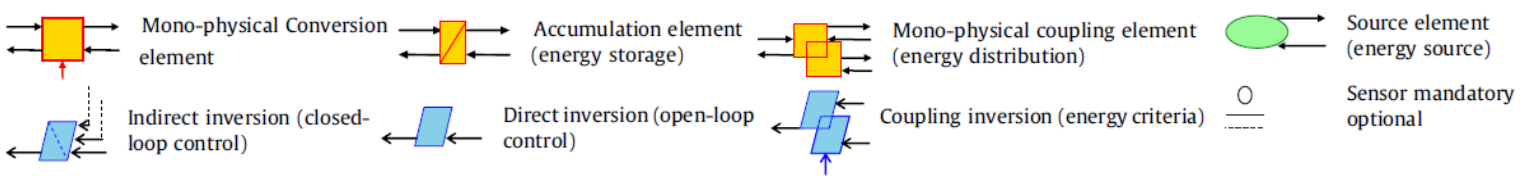

\section{References}

[1] 'Transport et CO2: quelle part des émissions ?' https://www.futurasciences.com/planete/questionsreponses/pollution-transport-co2-partemissions-1017/ (accessed Apr. 30, 2021).

[2] T. Mesbahi, P. Bartholomeus, N. Rizoug, R. Sadoun, F. Khenfri, and P. L. Moigne, 'Advanced Model of Hybrid Energy Storage System Integrating Lithium-Ion Battery and Supercapacitor for Electric Vehicle Applications', IEEE Trans. Ind. Electron., vol.
68, no. 5, pp. 3962-3972, May 2021, doi: 10.1109/TIE.2020.2984426.

[3] Y. Li, X. Huang, D. Liu, M. Wang, and J. Xu, 'Hybrid energy storage system and energy distribution strategy for four-wheel independent-drive electric vehicles', Journal of Cleaner Production, vol. 220, pp. 756-770, May 2019, doi: 10.1016/j.jclepro.2019.01.257.

[4] T. D. Atmaja and Amin, 'Energy Storage System Using Battery and Ultracapacitor on Mobile Charging Station for Electric Vehicle', Energy Procedia, vol. 68, pp. 429-437, Apr. 2015, doi: 10.1016/j.egypro.2015.03.274. 
[5] C. Capasso and O. Veneri, 'Integration between Super-capacitors and ZEBRA Batteries as High Performance Hybrid Storage System for Electric Vehicles', Energy Procedia, vol. 105, pp. 2539-2544, May 2017, doi: 10.1016/j.egypro.2017.03.727.

[6] D.-D. Tran, M. Vafaeipour, M. El Baghdadi, R. Barrero, J. Van Mierlo, and O. Hegazy, 'Thorough state-of-the-art analysis of electric and hybrid vehicle powertrains: Topologies and integrated energy management strategies', Renewable and Sustainable Energy Reviews, vol. 119, p. 109596, Mar. 2020, doi: 10.1016/j.rser.2019.109596.

[7] S. F. Tie and C. W. Tan, 'A review of energy sources and energy management system in electric vehicles', Renewable and Sustainable Energy Reviews, vol. 20, pp. 82-102, Apr. 2013, doi: 10.1016/j.rser.2012.11.077.

[8] R. Xiong, H. Chen, C. Wang, and F. Sun, 'Towards a smarter hybrid energy storage system based on battery and ultracapacitor A critical review on topology and energy management', Journal of Cleaner Production, vol. 202, pp. 1228-1240, Nov. 2018, doi: 10.1016/j.jclepro.2018.08.134.

[9] Q. Zhang and G. Li, 'Experimental Study on a Semi-Active Battery-Supercapacitor Hybrid Energy Storage System for Electric Vehicle Application', IEEE Trans. Power Electron., vol. 35 , no. 1 , pp. 1014-1021, Jan. 2020, doi: 10.1109/TPEL.2019.2912425.

[10] J. P. Trovao, M. R. Dubois, M.-A. Roux, E. Menard, and A. Desrochers, 'Battery and SuperCapacitor Hybridization for a Pure Electric Three-Wheel Roadster', in 2015 IEEE Vehicle Power and Propulsion Conference (VPPC), Montreal, QC, Canada, Oct. 2015, pp. 1-6. doi: 10.1109/VPPC.2015.7352904.

[11] Fanning Jin, Mengqi Wang, and Changjian Hu, 'A fuzzy logic based power management strategy for hybrid energy storage system in hybrid electric vehicles considering battery degradation', in 2016 IEEE Transportation Electrification Conference and Expo (ITEC), Dearborn, MI, USA, Jun. 2016, pp. 1-7. doi: 10.1109/ITEC.2016.7520207.

[12] 'GTCAP-2019-products-catalogue.pdf'.

Accessed: May 19, 2021. [Online]. Available: https://asdtc.co.uk/wpcontent/uploads/2019/08/GTCAP-2019products-catalogue.pdf

[13] B.-H. Nguyen, R. German, J. P. F. Trovao, and
A. Bouscayrol, 'Real-Time Energy

Management of Battery/Supercapacitor Electric Vehicles Based on an Adaptation of Pontryagin's Minimum Principle', IEEE Trans. Veh. Technol., vol. 68, no. 1, pp. 203-212, Jan. 2019, doi: 10.1109/TVT.2018.2881057.

[14] R. L. Spyker and R. M. Nelms, 'Classical Equivalent Circuit Parameters for a DoubleLayer Capacitor', vol. 36, no. 3, p. 8, 2000.

[15]Z. Song, H. Hofmann, J. Li, J. Hou, X. Han, and M. Ouyang, 'Energy management strategies comparison for electric vehicles with hybrid energy storage system', Applied Energy, vol. 134, pp. 321-331, Dec. 2014, doi: 10.1016/j.apenergy.2014.08.035.

[16] H. Yin, W. Zhou, M. Li, C. Ma, and C. Zhao, 'An Adaptive Fuzzy Logic-Based Energy Management Strategy on Battery/Ultracapacitor Hybrid Electric Vehicles', IEEE Trans. Transp. Electrific., vol. 2, no. 3, pp. 300-311, Sep. 2016, doi: 10.1109/TTE.2016.2552721.

[17] A. Castaings, W. Lhomme, R. Trigui, and A. Bouscayrol, 'Comparison of energy management strategies of a battery/supercapacitors system for electric vehicle under real-time constraints', Applied Energy, vol. 163, pp. 190-200, Feb. 2016, doi: 10.1016/j.apenergy.2015.11.020.

[18] J.-P. Hautier and P.-J. Barre, 'The Causal Ordering Graph A tool for system modelling and control law synthesis', p. 20.

[19]A. Bouscayrol, X. Guillaud, P. Delarue, and B. Lemaire-Semail, 'Energetic Macroscopic Representation and Inversion-Based Control Illustrated on a Wind-Energy-Conversion System Using Hardware-in-the-Loop Simulation', IEEE Trans. Ind. Electron., vol. 56, no. 12, pp. 4826-4835, Dec. 2009, doi: 10.1109/TIE.2009.2013251.

[20] P. J. Barrre et al., 'Inversion-based control of electromechanical systems using causal graphical descriptions', in IECON 2006 - 32nd Annual Conference on IEEE Industrial Electronics, Paris, France, Nov. 2006, pp. 5276-5281. doi: 10.1109/IECON.2006.347781.

[21] A. Bouscayrol et al., 'Control structures for multi-machine multi-converter systems with upstream coupling', Mathematics and Computers in Simulation, vol. 63, no. 3-5, pp. 261-270, Nov. 2003, doi: 10.1016/S03784754(03)00074-0. 